\title{
Bisphosphonate treatment for type III osteogenesis imperfecta in Lady Ridgeway Hospital, Colombo, Sri Lanka
}

\author{
S K Wijewardena ${ }^{1}$, C Kekulawala ${ }^{1}$, P D N de Silva ${ }^{2}$, M de Almeida ${ }^{3}$, B J C Perera ${ }^{2}$ \\ Sri Lanka Journal of Child Health, 2010; 39: 44-46 \\ (Key words: biphosphonate therapy, intravenous pamidronate, osteogenesis imperfecta, Sri Lanka)
}

\begin{abstract}
Objective: To ascertain clinical outcome following cyclical intravenous pamidronate therapy in a group of infants and young children with type III osteogenesis imperfecta (OI).
\end{abstract}

Design, setting and method: A prospective observational study was carried out on infants and young children referred to Ward 9 Lady Ridgeway Hospital (LRH) for assessment and treatment of OI from January 2005 to February 2007. All were treated with cyclical high dose intravenous pamidronate. Data collected included clinical history, treatment history, dose and frequency of treatment, adverse effects of the drug and outcome of treatment.

Results: Thirteen patients with clinical presentations compatible with type III OI were referred to Ward 9 LRH during the study period. Ten had fractures during fetal life and three presented with fractures during infancy. Age at commencement of the drug varied from 3 weeks to 42 months (median 10 months). The patients were followed up for periods ranging from 3 to 24 months. Four out of the 13 patients developed new fractures during follow up.

Conclusion: Intravenous high dose cyclical pamidronate is a useful form of therapy to prevent recurrent fractures in infants and young children with type III OI.

\section{Introduction}

Osteogenesis imperfecta (OI) is characterized by increased bone fragility and is often associated with joint hypermobility ${ }^{1}$. It is the most common genetic cause of osteoporosis ${ }^{2}$. The global incidence of this

${ }^{1}$ Senior Registrar, ${ }^{2}$ Consultant Paediatrician,
${ }^{3}$ Consultant Orthopaedic Surgeon, Lady Ridgeway
Hospital, Colombo.

(Received 24 April 2009. Accepted 20 May 2009) condition is 1 in 20,000 and it is a dominantly inherited bone disorder that occurs in all racial groups ${ }^{2}$. The bone pathology is due to structural or quantitative defect in type I collagen. Manifestations range from the lethal perinatal form to a mild disease which manifests at an older age ${ }^{2}$.

There are five clinical types. Type II is the most severe form. Affected infants may be stillborn. There can be multiple intrauterine fractures of long bones and ribs which have a crumpled appearance on radiographs. Severely affected infants are small for gestational age. There is striking micromelia and bowing of extremities. Their small thoracic cavity contributes to severe respiratory insufficiency and infant death ${ }^{2,3}$.

Type III is the most severe nonlethal form. Their birth weights and lengths are often lower than normal. Fractures usually occur in-utero. There is relative macrocephaly and a triangular facies. Postnatal fractures occur from inconsequential trauma and heal with deformities. All type III patients have extremely short stature by the first year. They get severe kyphosis, scoliosis, vertebral compression fractures and basilar invagination which leads to severe long term morbidity and mortality ${ }^{2,4}$.

Milder forms (types I and IV) present with recurrent fractures, progressive deformities, short stature and chronic bone pain. Fracture rates decrease after puberty and they are usually able to attain community ambulation skills ${ }^{2,5,6}$. Type $\mathrm{V}$ is a distinct type within type IV. These patients have hyperplastic callus, calcification of the intraosseous membrane of the forearm and a radio-dense metaphyseal band ${ }^{2}$.

A definitive treatment for OI is yet to be established. Current therapeutic options include growth hormone, bisphosphonates, gene therapy and bone marrow transplantation. There have been promising results with cyclical administration of bisphosphonates, especially intravenous pamidronate in children with OI, from neonatal age up to adolescence $e^{2,3,4,5,7}$. The 
mechanism of action of bisphosphonates is inhibition of the osteoclastic activity. This reduces excessive bone resorption by osteoclasts. As a result bone fragility is decreased ${ }^{2}$.

\section{Method}

A prospective observational study was carried out on children with OI referred to ward 9 Lady Ridgeway Hospital (LRH) for assessment and treatment from $1^{\text {st }}$ January 2005 to $1^{\text {st }}$ February 2007. They were given IV pamidronate $2-3 \mathrm{mg} / \mathrm{kg} /$ day diluted in $100 \mathrm{ml}$ of normal saline as an infusion over 1-2 hours daily on 3 consecutive days. This regimen was repeated cyclically at intervals varying from 3-6 months depending on the severity of presentation. Data collection was done by entering details into a clinical record form. Data included clinical history, dosage of pamidronate, frequency of administration of the drug, adverse effects and clinical outcome following treatment.

\section{Results}

Thirteen patients with OI were referred to Ward 9 LRH during the period of study. All thirteen patients were clinically compatible with type III OI. Ten had fractures during fetal life. The other three patients presented with fractures during infancy. Age at commencement of the drug varied from 3 weeks to 42 months (median age 10 months). The patients were followed up for periods ranging from 3-24 months. The age of presentation, the frequency of fractures before and after commencement of treatment and duration of follow up are given in Table 1 .

Table 1

Age of presentation, frequency of fractures before and after commencement of treatment and duration of follow up

\begin{tabular}{|c|c|c|c|c|}
\hline \multirow{2}{*}{$\begin{array}{c}\text { Patient } \\
\text { Number }\end{array}$} & $\begin{array}{c}\text { Age of } \\
\text { presentation }\end{array}$ & \multicolumn{2}{|c|}{ Number of fractures } & $\begin{array}{c}\text { Duration of follow up by 1 } \\
\text { February 2007 }\end{array}$ \\
\cline { 3 - 5 } & & Before treatment & After treatment & 6 months \\
\hline 1 & 7 months & 04 & 00 & 7 months \\
\hline 2 & 13 months & 10 & 00 & 8 months \\
\hline 3 & 1 month & 04 & 00 & 24 months \\
\hline 4 & 3 weeks & 05 & 00 & 9 months \\
\hline 5 & 11 months & 10 & 00 & 4 months \\
\hline 6 & 2 months & 06 & 00 & 24 months \\
\hline 7 & 42 months & 08 & 00 & 3 months \\
\hline 8 & 30 months & 03 & 00 & $21 / 2$ months \\
\hline 9 & 5 weeks & 06 & 00 & 24 months \\
\hline 10 & 10 months & 10 & 03 & 24 months \\
\hline 11 & 6 months & 02 & 01 & 13 months \\
\hline 12 & 6 months & 04 & 03 & 05 \\
\hline 13 & 18 months & 08 & & \\
\hline
\end{tabular}

Nine $(69 \%)$ of the 13 patients given IV pamidronate had no new fractures after commencement of therapy. Four (31\%) patients developed one or more new fractures during follow up but in two of them the expected incidence of new fractures was markedly reduced.

One child developed a generalised tonic clonic hypocalcaemic seizure during the infusion which lasted about 2 minutes and resolved spontaneously without any undue effects.

\section{Discussion}

In our study there was a good response to treatment with cyclical high dose intravenous pamidronate, all patients showing reduced incidence of fractures and $69 \%$ developing no new fractures. The efficacy of the drug is comparable to that in other studies in Sri Lanka and elsewhere ${ }^{3,4,5,7}$.

There were no significant side effects of the treatment apart from one transient episode of hypocalcaemic convulsions which resolved spontaneously.

In a similar prospective observational study, with a historic control group, intravenous pamidronate was given as monthly infusions to 11 children with severe OI aged 3-13 (median 3.6) months. During treatment of children aged between 3 and 6 (median 4.5) years, dual-energy $\mathrm{x}$ ray absorptiometry measurements of the lumbar spine showed a gradual increase in bone density. Bone metabolism parameters in serum and urine indicated a decrease in bone turnover. An improvement of mobility was seen and at the last 
recording, at the age of 3.3-6.5 (median 4.8) years, the children could all walk well. Vertebral remodelling was seen, with increased vertebral height, and no child developed scoliosis, kyphosis or basilar impression. All these children required femoral intramedullary rods for fractures, and five needed tibial rodding for extreme curvatures that prevented functional standing and walking. No adverse effects were seen on growth, fracture healing or blood chemistry. Cyclical pamidronate treatment combined with proper orthopaedic management significantly improved mobility, ambulation level, and muscle force in children with moderate to severe $\mathrm{OI}^{3,4,5}$.

\section{Conclusion}

Intravenous high dose cyclical pamidronate is likely to be an effective symptomatic treatment for prevention of fractures in infants and young children with type III OI.

\section{Acknowledgements}

The help of medical and nursing staff ward 09, LRH, the child patients and their parents is gratefully acknowledged.

\section{References}

1. McIntosh N, Helmes PJ, Smith RL, editors. Forfar and Arneil Text book of Paediatrics, $6^{\text {th }}$ ed. London: Churchill Livingstone; 2003 p. 1539.

2. Behrman $\mathrm{R}$ E, Kliegman $\mathrm{R} \mathrm{M}$, Jenson $\mathrm{H} \mathrm{B}$, editors. Nelson Text book of Paediatrics $17^{\text {th }}$ ed. Philadelphia: WB Saunders; 2004 p. 2336-8.

3. Land C, Rauch F, Montpetit K, Ruck-Gibis J, Glorieux FH. Cyclic administration of pamidronate in children with severe osteogenesis imperfecta, New England Journal of Medicine 1998: 339:947-52.

4. Aström E, Jorulf H, Söderhäll S. Intravenous pamidronate treatment of infants with severe osteogenesis imperfecta. Archives of Disease in Childhood 2007; 92: 332-8.

5. Aström E, Jorulf H, Söderhäll S. Beneficial effects of bisphosphonates during treatment of severe osteogenesis imperfecta. Acta Paediatrica 1998: 97:64-8

6. Ruukh F, et.al, The effects of intravenous pamidronate on the bone tissue of children and adolescents with osteogenesis imperfecta, Journal of Clinical Investigation 2003; 110: 1293-9

7. Amarasena S, et.al. Cyclical intravenous pamidronate therapy in children with osteogenesis imperfecta. Sri Lanka Journal of Child Health 2005; 50:137-8 